\title{
EFFECT OF GENE POLYMORPHISMS IN ANTIOXIDANT ENZYMES ON OXIDATIVE-ANTIOXIDATIVE STATUS IN YOUNG MEN
}

\author{
JADWIGA KOTOWSKA, EWA JÓWKO
}

\author{
Józef Pitsudski University of Physical Education in Warsaw, Faculty of Physical Education and Health, \\ Department of Natural Sciences, Biała Podlaska, Poland
}

\author{
Mailing address: Jadwiga Kotowska, Józef Piłsudski University of Physical Education in Warsaw, Faculty of Physical \\ Education and Health in Biała Podlaska, 2 Akademicka Street, 21-500 Biała Podlaska, tel.: +48 83 3428773, \\ e-mail: jadwiga.kotowska@awf-bp.edu.pl
}

\begin{abstract}
Introduction. The aim of the study was to evaluate the relationship between SOD1 +35A/C, SOD2 Val16Ala and GPx1 Pro198Leu gene polymorphisms and baseline level of oxidative-antioxidative status in blood. Material and methods. The study included 154 male students of physical education who participated in practical classes included in the study curriculum. Genotyping was carried out on genomic DNA using real-time PCR reaction with TaqMan assays. Also, fasting blood samples were analyzed for biochemical parameters including superoxide dismutase (SOD) activity in erythrocytes and the activity of glutathione peroxidase (GPx) in whole blood, as well as serum concentration of lipid hydroperoxides (LOOHs) and total antioxidant capacity (TAC) of serum. Results. SOD2 polymorphism had a significant effect on serum LOOHs concentration. Individuals with Val/ Val genotype presented a significantly higher level of LOOHs than Val/Ala genotype carriers $(\mathrm{p}<0.05)$. In addition, no significant differences in SOD and GPx activity or TAC were found between SOD2 genotypes. Apart from the SOD2 polymorphism, no significant influence of both SOD1 and GPxl polymorphisms on measured biochemical parameters was found, probably due to the lack of mutant homozygous genotypes in the study group. Conclusions. In young, healthy and physically active men, SOD2 polymorphism has an influence on the resting level of oxidative stress marker in the blood without affecting both enzymatic and non-enzymatic antioxidant defence. In turn, SOD1 and GPxl polymorphisms do not seem to affect oxidative-antioxidative status. However, the absence of SOD1 CC and GPxl Leu/Leu may indicate that these genotypes are disadvantageous, and thus underrepresented in young, healthy and physically fit population.
\end{abstract}

Key words: gene polymorphism, oxidative stress, lipid peroxidation, antioxidant enzymes

\section{Introduction}

The oxygen metabolism in the mitochondria of aerobic organisms causes the formation of reactive oxygen species (ROS) [1]. Physiological concentrations of ROS are favourable because of their regulatory role, e.g. in cell signaling pathways or gene expression $[2,3,4,5,6]$. However, elevated ROS level causes an imbalance between ROS and antioxidants, known as oxidative stress [5, 7], which can lead to oxidative damage of cell structures, among others DNA, proteins and membrane lipid (peroxidation) $[1,7,8]$. Intense physical exercise increases oxygen uptake, which contributes to the increased production of ROS (depending on the intensity and duration of the exercise) [9], and in turn to exercise-induced oxidative stress [6].

The first line of defence against ROS in mitochondria is provided by mitochondrial isoenzyme of superoxide dismutase (manganese-containing SOD named as MnSOD/SOD2), which catalyzes the dismutation of superoxide radicals to hydrogen peroxide $\left(\mathrm{H}_{2} \mathrm{O}_{2}\right)$ and oxygen [10]. Then, $\mathrm{H}_{2} \mathrm{O}_{2}$ is decomposited to $\mathrm{H}_{2} \mathrm{O}$ by catalase enzyme (CAT) or glutathione peroxidase (GPx) [11]. Human SOD2 gene is located on chromosome 6 (6q25.3.) and its protein product, after translation in cytosol, is transported to mitochondria. It is commonly believed that the cellular defence against harmful effects of ROS depends on the polymorphism in the SOD2 gene. The most commonly analyzed single nucleotide polymorphism (SNP) on SOD2 gene is Vall6Ala (rs 4880) in mitochondrial target sequence (MTS). Substitution of $\mathrm{T}$ (thymine) for $\mathrm{C}$ (cytosine) in exon 2 causes translation of valine amino acid (GTT) into alanine (GCT) at the protein level. The result is a protein with a changed secondary structure. As reported, Ala variant is correctly transported through mitochondria membranes, while Val variant is partially arrested in the mitochondria inner membrane [12]. It has been suggested that SOD2 gene polymorphism contribute to differentiation of antioxidant capacity in the human population [1] with Val/Val genotype being related to decreased SOD2 efficiency against oxidative stress [12].

In fact, Vall6Ala SOD2 polymorphism has been associated with different oxidative stress-related pathologies [13, 14, 15]. Moreover, the relationship between SOD2 gene polymorphism and oxidative stress/muscle damage markers has also been demonstrated with exercise.

In the study of Bresciani et al. [16], intense physical exercise resulted in higher content of SOD2 protein in leukocytes of Ala/Ala carriers in comparison with Val/Val individuals. In turn, Ahmetov et al. [17] found that Val/Val genotype is significantly less common in high- intensity group of elite athletes compared to both the control group and the low-intensity group. Also, as reported in that study [17], in comparison with SOD2 Ala/Ala genotype carriers, Val allele carriers exhibited higher activity of creatine kinase (CK) in the blood, as a marker of muscle damage. They also suggested that Val/Val SOD2 genotype might be unfavourable for high-intensity athletic events. In turn, Akimoto et al. [7] reported an association between Ala/Ala genotype and lower muscle damage, based on values of plasma CK in runners. Vecchio et al. [18] found that water polo players having the 
SOD2 Val/Val genotype had significantly higher post-exercise levels of $\mathrm{CK}$ and myoglobin in the blood in comparison with Ala/Ala genotype or heterozygote Ala/Val. Also, they observed higher levels of oxidative stress before and after exercise in athletes carrying Val allele, as compared to subjects with Ala/Ala genotype. However, no measurements of antioxidant enzyme activities (SOD, CAT, GPx) were conducted in the above cited study [18].

In addition to the SOD2 polymorphism, other polymorphisms have been reported in genes encoding antioxidant enzymes (such as SODl and GPxl), which affect oxidative stress biomarkers, mainly under pathological conditions. One of them is the substitution of T for C (C593T) in the GPxl gene, which results in a proline to leucine change at codon position 198 (Prol98Leu). The Leu allele was reported to be associated with decreased GPxl enzymatic activity, as compared to the wild-type Pro allele $[19,20]$. In turn, as confirmed by Thu et al. [21], diminished GPx activity may lead to increased oxidative damage. In fact, increased mitochondrial $\mathrm{H}_{2} \mathrm{O}_{2}$ production and mtDNA damage were found in GPxl knockout $\left(\mathrm{GPxl}^{-/-}\right)$mice as compared to wild-type $\left(\mathrm{GPxl}^{+/+}\right)$mice [21]. A link between GPxl polymorphism and oxidative stress-related disorders has been reported by many authors. It has been indicated that Leu allele may be a risk allele of breast [19], bladder [22] and lung [23] cancer. However, the results of other studies are inconclusive. Forsberg et al. [24] indicated that erythrocyte GPx activity did not vary with GPxl genotype in the Finnish/Swedish population. In contrast to Ratnasinge et al. [23], Raaschou-Nielsen et al. [25] noted that Leu/Leu genotype was associated with a lower risk of lung cancer than Pro/Pro genotype. Similar results were obtained by Arsova-Sarafinowska et al. [26] in the study of prostate cancer risk, demonstrating protective effect of the Leu allele.

SOD1 $+35 \mathrm{~A} / \mathrm{C}$ gene polymorphism is another one which has been linked to the activity of enzymatic antioxidant system. The human SOD1 gene is localized on chromosome 21(2lq22.1). It has five exons and the $+35 \mathrm{~A} / \mathrm{C}$ polymorphism is adjacent to the splicing point (exon3/intron3) [27]. Flekac et al. [28] and Ghattas et al. [27] found lower serum SOD activity in CC than in AA genotypes of diabetic patients. As it has been mentioned before, decreased antioxidant defence may be related to various oxidative stress disorders. Flekac et al. [28] found association between SOD1 gene polymorphism and macroangiopathy in type 2 diabetes mellitus (T2DM) patients. In turn, Panduru et al. [29] showed the relationship between CC genotype and advanced stages of diabetic nephropathy in patients with type 1 diabetes. According to the above, Akhy et al. [30] indicated that this mutation in SODl gene may be linked to the development of nephropathy in diabetic population in Bangladesh. In contrast, Ukkola et al. [31] reported no association between SODl gene polymorphism and cardiovascular disease in T2DM patients. Moreover, $\mathrm{C}$ allele was completely absent in type 2 diabetes mellitus in both South Indian [32] and North Indian population [33].

However, there is a lack of studies on a potential relationship between these polymorphisms and oxidative stress markers in young healthy population. Therefore, the aim of our study was to evaluate the distribution of SOD2, SOD1 and GPxl genotypes in healthy, physically active men (physical education students) and the relationship between these gene polymorphisms and the baseline level of oxidative stress marker (lipid peroxidation) and antioxidant defence in blood (i.e. oxidative-antioxidative status).

\section{Material and methods}

\section{Subjects}

The study included 154 Polish (Caucasian) male students of physical education from the Faculty of Physical Education and Health in Biala Podlaska who participated in practical classes included in the study curriculum. However, none of the study subjects engaged in any regular exercise training regimens at the time of enrolment. Exclusion criteria of the study were as follows: the use of tobacco products, alcohol consumption, a history of recent surgery or illness and intake of medications or dietary supplements during four weeks preceding the study. The protocol of the study was approved by the Local Bioethics Committee at the University of Physical Education in Warsaw, and the research was conducted in accordance with the principles stated in the Declaration of Helsinki.

\section{Blood sampling and biochemical analyses}

Fasting blood samples were taken from the ulnar vein in the morning (at 7:00 a.m.). All the subjects had not eaten any food for 10-12 hours and had not exercised for 24 hours prior to blood drawing. The samples were collected using test tubes with EDTA (for the whole blood, erythrocyte and DNA isolation) and without anticoagulants (for separation of serum). In order to form blood clot, the samples were exposed to room temperature, and then centrifuged (for 10 minutes at $3000 \mathrm{x}$ g at a temperature of $4^{\circ} \mathrm{C}$ ) to separate serum. Also, the portion of the blood with EDTA was centrifuged to separate erythrocytes and plasma. Subsequently, the erythrocytes were washed three times with a cold isotonic saline solution. Erythrocytes, serum and whole blood were frozen and stored at $-80^{\circ} \mathrm{C}$ until analysis.

The list of analyzed biochemical parameters included erythrocyte activity of SOD and activity of glutathione peroxidase (GPx) in whole blood, as well as serum concentration of lipid hydroperoxides (LOOHs) and total antioxidant capacity of serum (TAC).

SOD and GPx activities were determined with commercially available kits (RANSOD Cat. No. SD 125 and RANSEL Cat. No. RS 505, respectively; Randox, Crumlin, UK). The enzymatic activities were measured at $37^{\circ} \mathrm{C}$ and expressed in $\mathrm{U} / \mathrm{g} \mathrm{Hb}$. Concentration of haemoglobin was determined with a standard cyanmethemoglobin method, using a commercially available diagnostic kit (HG 1539; Randox, Crumlin, UK).

LOOHs levels were determined as described previously [34]. The assay is based on the reaction of a chromogenic reagent, $\mathrm{N}$-methyl-2-phenylindole, with malondialdehyde and 4-hydroxyalkenals at $45^{\circ} \mathrm{C}$. As a result, a stable chromophore is formed with maximum absorbance at $586 \mathrm{~nm}$.

The total antioxidant capacity (TAC) of serum to scavenge ABTS (2,2'-Azino-di-[3-ethylbenzthiazoline sulphonate]) radicals was measured using a chromogenic method with a commercially available kit (Randox, Crumlin, UK). The antioxidant capacity of samples was expressed as millimoles per liter of Trolox equivalents (6-hydroxy-2,5,7,8-tetramethylchroman-2-carboxylic acid).

\section{Genotyping}

Genomic DNA for genotyping was isolated from peripheral venous blood using QIAamp DNA Blood Mini Kit (Qiagen $\mathrm{GmbH}$, Hilden, Germany). Concentration of DNA was determined with Picodrop microliter spectrophotometer (PicoDrop, UK). The following gene polymorphisms were genotyped: SOD1 +35A/C (rs2234694), SOD2 Vall6Ala (rs4880) and GPxl Pro198Leu (rs1050450). Genotyping for all gene polymorphisms 
was carried out by a 10- $\mu \mathrm{L}$ PCR reaction on DNA (50 ng) using a TaqMan PCR Master Mix (Applied Biosystems) and fluorescent 5'- exonuclease TaqMan SNP assays (Applied Biosystems, Foster City, CA, USA) with FAM and VIC fluorophore-labeled probes. Real-time PCR was performed on Rotor Gene (Qiagen $\mathrm{GmbH}$, Hilden, Germany), according to the following protocol: an initial 5 minutes at $95^{\circ} \mathrm{C}$ followed by 45 cycles of 15 seconds at $95^{\circ} \mathrm{C}, 30$ seconds at $60^{\circ} \mathrm{C}, 30$ seconds at $72^{\circ} \mathrm{C}$, and finally 8 minutes at $72^{\circ} \mathrm{C}$. SOD1 (rs2234694), SOD2 (rs4880) and GPxl (rs1050450) were genotyped with a commercially available TaqMan kit (C_34770911_10, C_8709053_10, C_175686987_10 AB assay, respectively, Applied Biosystems, Foster City, CA, USA).

\section{Statistical analysis}

For each SNP, deviation of the genotype frequencies from those expected under the Hardy-Weinberg equilibrium was assessed with chi-square $(\chi 2)$ test [35]. Biochemical parameters in genotypes were analyzed with one-way ANOVA using Statistica version 13.3 software package (StatSoft, Krakow, Poland) with the Bonferroni post-hoc test for multiple comparisons. The normal distribution of all variables was confirmed with the Shapiro-Wilk test and visual inspection (quantile distribution plots). All values were reported as mean \pm standard deviation (SD). The level of statistical significance was set at $\mathrm{p}<0.05$.

\section{Results}

Anthropometric characteristics of the study participants are shown in Table 1.

The Vall6Ala SOD2 and +35 A/C SOD1 polymorphism genotype distribution (Tab. 2) was in agreement with the Hardy-Weinberg equilibrium ( $\mathrm{p}=0.65 ; \mathrm{p}=0.44$, respectively). Genotype frequencies for SOD2 were 29\% for Val/Val, 48\% for Val/Ala and 23\% for Ala/Ala. Genotype frequencies for SOD1 were $88 \%$ for $\mathrm{AA}$ and $12 \%$ for $\mathrm{AC}$, whereas CC genotype was absent in the study group.

Contrary to SOD2 and SOD1 polymorphisms, the distribution of Prol98Leu of GPxl genotypes deviated from the Har$\mathrm{dy}$-Weinberg equilibrium ( $\mathrm{p}<0.00001$ ), at the following genotype frequency: $45 \%$ for Pro/Pro, 55\% for Pro/Leu, and with the absence of Leu/Leu genotype in the study group (Tab. 2).

Table 3 presents mean values of biochemical parameters in the whole study group as well as in individual genotypes within SOD1, SOD2 and GPx polymorphisms. There were no significant differences in SOD and GPx activity nor in TAC between SOD2 Vall6Ala genotypes ( $\mathrm{p}>0.05$ for each mentioned parameter). However, SOD2 Vall6Ala polymorphism had a significant effect on serum LOOHs concentration. Individuals with Val/Val genotype presented significantly higher levels of LOOHs in serum than Val/Ala genotype carriers ( $<$ 0.05) (Tab. 3).

Apart from the SOD2 polymorphism, no significant influence of both SODl and GPxl polymorphism on the measured biochemical parameters was found ( $\mathrm{p}>0.05)$ (Tab.3).

\section{Discussion}

The balance between the production of free radicals and the antioxidant defence in the body has important health implications. This balance can be disturbed by many environmental factors, even under physiological conditions (e.g. intense physical exercise). Also, it has been suggested that susceptibility to oxidative stress may be genetically determined. Antioxidant defence is available to combat ROS; however, individuals may
Table 1. Anthropometric characteristic of study participants (mean \pm SD)

\begin{tabular}{|c|c|}
\hline Age (years) & $21.22 \pm 1.69$ \\
\hline Body height $(\mathrm{cm})$ & $181.35 \pm 5.56$ \\
\hline Body mass $(\mathrm{kg})$ & $78.51 \pm 9.19$ \\
\hline BMI $\left(\mathrm{kg} / \mathrm{m}^{2}\right)$ & $23.85 \pm 2.36$ \\
\hline
\end{tabular}

* - BMI body mass index

Table 2. The distribution of genotypes for gene polymorphisms in the studied students (n, (\%))

\begin{tabular}{|c|c|c|}
\hline POLYMORPHISM & $\begin{array}{c}\text { The whole group } \\
(\mathbf{n}=\mathbf{1 5 4})\end{array}$ & HWE \\
\hline SOD1 +35 A/ C & $136(88)$ & $\times 2=0.59$ \\
AA & $18(12)$ & $p=0.44$ \\
AC & 0 & \\
CC & $44(29)$ & $\times 2=0.20$ \\
SOD2 Val16Ala & $74(48)$ & $p=0.65$ \\
Val/Val & $36(23)$ & \\
Val/Ala & & \\
Ala/Ala & $70(45)$ & $\mathrm{X} 2=21.67$ \\
GPx Pro198Leu & $84(56)$ & $\mathrm{p}=0.0000003$ \\
Pro/Pro & 0 & \\
Pro/Leu & & \\
Leu/Leu &
\end{tabular}

HWE - Hardy-Weinberg equilibrium; $\chi 2$ - chi-square; $p$ - values.

Table 3. Biochemical parameters stratified according to the polymorphisms in SOD1, SOD2 and GPx genes

\begin{tabular}{|c|c|c|c|c|}
\hline & 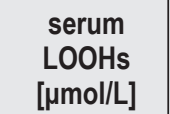 & $\begin{array}{c}\text { serum TAC } \\
{[\mathrm{mmol} / \mathrm{L}]}\end{array}$ & $\begin{array}{l}\text { whole blood } \\
\text { GPx [U/gHb] }\end{array}$ & $\begin{array}{c}\text { erythrocyte SOD } \\
{[\mathrm{U} / \mathrm{gHb}]}\end{array}$ \\
\hline $\begin{array}{c}\text { Whole } \\
\text { study group }\end{array}$ & $3.45 \pm 1.62$ & $1.8 \pm 0.21$ & $44.72 \pm 19.06$ & $1560.34 \pm 416.55$ \\
\hline SOD1 $1+35$ & $\mathrm{~A} / \mathrm{C})$ & & & \\
\hline $\mathrm{A} / \mathrm{A}$ & $3.44 \pm 1.65^{\mathrm{a}}$ & $1.8 \pm 0.20^{a}$ & $44.56 \pm 19.61^{a}$ & $1548.35 \pm 419.77 \mathrm{a}$ \\
\hline $\mathrm{A} / \mathrm{C}$ & $3.58 \pm 1.58^{\mathrm{a}}$ & $1.81 \pm 0.26 \mathrm{a}$ & $45.73 \pm 19.58^{a}$ & $1553.65 \pm 362.67 a$ \\
\hline SOD2 (Val16 & 6Ala) & & & \\
\hline $\mathrm{Val} / \mathrm{Val}$ & $3.89 \pm 1.97 \mathrm{a}$ & $1.78 \pm 0.2^{\mathrm{a}}$ & $46.86 \pm 22.40^{a}$ & $1561.71 \pm 364.03^{a}$ \\
\hline Val/Ala & $3.24 \pm 1.47^{b}$ & $1.81 \pm 0.21 \mathrm{a}$ & $43.41 \pm 17.60^{a}$ & $1579.58 \pm 481.07 \mathrm{a}$ \\
\hline Ala/Ala & $3.38 \pm 1.38^{\mathrm{ab}}$ & $1.82 \pm 0.22^{\mathrm{a}}$ & $44.79 \pm 17.79 a$ & $1519.13 \pm 332.36^{a}$ \\
\hline GPx (Pro198 & 8Leu) & & & \\
\hline Pro/Pro & $3.42 \pm 1.73^{a}$ & $1.81 \pm 0.20^{\mathrm{a}}$ & $42.74 \pm 16.99^{a}$ & $1513.18 \pm 402.47 \mathrm{a}$ \\
\hline Pro/Leu & $3.46 \pm 1.54^{\mathrm{a}}$ & $1.80 \pm 0.21 \mathrm{a}$ & $46.36 \pm 20.59^{a}$ & $1599.65 \pm 426.32^{a}$ \\
\hline
\end{tabular}

Values are means \pm SD. a,b - differences between genotypes (within the same polymorphism); values that do not have common letters are significantly different $(\mathrm{p}<0.05)$; In turn, values with the same letter are not significantly different ( $\mathrm{p}>0.05)$; LOOHs - lipid hydroperoxides; TAC - total antioxidant capacity; GPx - glutathione peroxidase; SOD superoxide dismutase; Activities of antioxidant enzymes in erythrocytes and whole blood are expressed in U per gram of haemoglobin [U/gHb]. 
vary in their capacity to deal with the oxidant burden because of some SNPs in antioxidant enzyme genes. Changes in the expression of these polymorphic genes may alter enzymatic activities that can lead to reduced protection from oxidative stress [36]. Therefore, the main aim of our research was to investigate, in the population of young, healthy and physically active people, whether the most common polymorphisms in gene encoding antioxidant enzymes (SOD1, SOD2 and GPxl) may have an impact on resting (baseline) values of the markers of oxidative-antioxidative homeostasis in blood.

The results of our study showed that SOD2 Vall6Ala polymorphism affects serum level of lipid peroxidation without affecting both enzymatic and non-enzymatic antioxidant potential of the blood. However, the oxidative-antioxidative status of the blood was not influenced by either SOD1 or GPx polymorphism.

It is well known that the mitochondrial manganese containing SOD2 is the primary antioxidant enzyme in the mitochondria. Apart from SOD2, there are also two other SOD isoforms that have been described in mammalian cells: the cytosolic copper/zinc-containing SOD1 (Cu/ZnSOD) and the extracellular copper/zinc-containing SOD3 (ECSOD)[12]. However, among the enzymes involved in antioxidant protection, SOD2 plays a key role in the aerobic organisms in the detoxification of superoxide free radicals. Thus, SOD2 isoenzyme protects cells from oxidative stress, particularly in the place perceived as the main source of their production, not only under exercise conditions [37].

There exists a lot of scientific evidence confirming beneficial effects of regular physical activity on oxidative-antioxidative status, decreasing the levels of free radical markers both at rest and after single intense physical exercise [38, 39]. Moreover, our previous study revealed that the response of oxidative-antioxidative status to sports training may be modulated by SOD2 Vall6Ala polymorphism [40]. Namely, we noted that long-term (12-week) swimming training in untrained men reduced the level of lipid peroxidation and muscle cell damage. Importantly, these favorable changes induced by periodic swimming training seemed to depend on the Ala/Ala genotype, as this genotype was associated with a significant decrease in both serum concentration of lipid hydroperoxides and serum CK activity [40]. In addition, in our another study on athletes (wrestlers) [41], Ala/Ala genotype was related to the lowest (from all three genotypes within SOD2 Vall6Ala polymorphism) level of serum hydroperoxides at rest.

Undoubtedly, our current study also confirms that SOD2 isoenzyme plays the most significant part in protecting against free radicals in physically active men, since among three polymorphisms studied only SOD2 polymorphism affected oxidative stress marker. More precisely, serum LOOHs level was significantly higher in Val/Val genotype than in Val/Ala genotype. Although serum LOOHs levels only tend to be significantly higher in the Val/Val genotype compared to the Ala/Ala genotype ( $p=0.1)$, all our observations (current and previous) put together may indicate that the Val allele is more susceptible to oxidative stress than the Ala allele. Our results are in accordance with the results of other studies reporting Val allele being associated with many oxidative stress-related conditions, like cardiovascular diseases $[13,14,15]$, hyperlipidemia $[42,43]$ or obesity [44]. Also, our finding is in line with previous studies reporting that Val allele may be related to intensified oxidative damage in untrained persons who underwent intense exercise [16], as well as in athletes' population, both at rest $[17,18]$ and post-exercise [18]. Admittedly, our subjects did not practice competitive sports or engage in any regular exercise training regimens, and they did not undergo intense exercise (i.e. we did not measure oxidative stress marker in exercise conditions). It must be emphasized, however, that as physical education students, they were physically active people participating in different types of practical classes included in their study curriculum, which may also contribute to some disturbance of the oxidative-antioxidative balance. This disturbance was rather related to the promotion of oxidative processes, but not to changes in antioxidant defence, since no association of SOD2 polymorphism with both enzymatic (i.e. erythrocytes SOD activity and the whole blood GPx activity) and non-enzymatic (i.e. serum TAC) antioxidant potential was seen in our study population.

Most studies in the available literature concern the relationship between SOD2 polymorphism and the occurrence of various oxidative stress-related diseases $[13,14,15,42,43,44]$. Few studies regarded the association of SOD2 genotypes and blood antioxidant enzyme activity in healthy untrained population, with contradictory results $[16,36]$. In the study of Bresciani et al. [16], in comparison to Ala/Ala genotype, Val/Val genotype was related to lower post-exercise SOD2 activity along with higher post-exercise level of free radical protein damage in peripheral blood leukocytes. In turn, Bastaki et.al [36] reported greater baseline SOD2 activity in erythrocytes in subjects carrying Val allele (Ala/Val and Val/Val genotypes) than in subjects with Ala/ Ala genotype.

In our research, we focused on examining potential differences in basal (resting) enzymatic activity depending on SOD2 genotypes in the population of physically active men. However, it is worth noting that our results are based on total SOD activity in erythrocytes, which represents mainly the activity of cytosolic $\mathrm{ZnCu}-\mathrm{SOD}$, and to a lesser extent the activity of SOD2 (MnSOD) itself. Thus, this may explain the lack of link between SOD2 polymorphism and total SOD activity in erythrocytes in the current study. Moreover, the level of the studied indicators varies individually (which we also observed in previous published studies), and it is possible that it may be influenced by lifestyle or dietary habits of the subjects, as well as other genetic factors apart from the examined. On the other hand, such a link was found in our previous studies on wrestlers [41] and untrained men undergoing long-term swimming training [40]. Therefore, it is most probable that SOD2 polymorphism can affect total SOD activity in erythrocytes, but only in exercise condition or in persons with high levels of adaptation to exercise (athletes).

The purpose of the current study was also to determine the frequency distribution of genotypes within SOD1, SOD2 and GPxl polymorphisms in healthy, physically active population. In the case of SOD2 polymorphism, the distribution was not different than expected from the Hardy-Weinberg equilibrium, and similar to that reported in other studies [16, 36].

According to GPxl polymorphism, we did not find any differences in blood oxidative-antioxidative status between GPxl genotypes. In the previous study on the population of young women and men of different ethnic origin, Bastaki et al. [36] evaluated the effect of GPxl polymorphism on blood GPx activity. They noted lower GPx activity in men with TT (Leu/Leu) genotype in comparison to men with CC (Pro/Pro) or CT (Pro/ Leu) genotypes. However, the lack of any differences in GPx activity between GPxl genotypes in our study probably results from the absence of Leu/Leu genotype in our study population. Moreover, in our population of healthy physically active men with Caucasian origin, the genotype frequencies in GPxl gene differed significantly from those predicted by the Hardy-Wein- 
berg equilibrium. Admittedly, Bastaki et al. [36] also observed a significant divergence in the distribution of GPx genotypes from the Hardy-Weinberg equilibrium, but only in the Asian/ Pacific Islander subgroup, but not in the Caucasian one. Other studies provide evidence that the Leu/Leu genotype may be unfavorable to health, indicating an increased risk of developing diseases for which free radicals play an important role in etiopathogenesis $[45,46]$. Although Bastaki et al. [36] did not measure any oxidative stress parameters, decreased GPx activity in Leu/Leu genotype in the study may indicate a deterioration in the antioxidant defence, and an increase in susceptibility to oxidative stress. Taking into account all the issues mentioned above, the lack of Leu/Leu genotype in our study population of physically active men may point to natural selection and the prevalence of Pro allele in healthy physically fit population.

Similar to GPx polymorphism, our study revealed no association of SODl polymorphism with both antioxidant enzyme defence and lipid peroxidation marker in blood. However, it must be emphasized that we did not find mutant homozygous genotype (i.e. SOD1 CC) in the study population. Although in this case the distribution of SODl genotypes did not deviate from the Hardy-Weinberg equilibrium, the lack of CC homozygote may confirm that A allele is disadvantageous to healthy physically fit population. Our suggestions can be confirmed by previous studies which showed a link between the SOD1 CC genotype and the deterioration of oxidative/antioxidative status under various pathological conditions [27, 28, 29, 30]. Also, the current findings have recently been confirmed in a group of 150 athletes of team games and combat sports (our data has not been published yet), as we have not found any person with CC genotype in this group, either.

\section{Conclusions}

In young, healthy and physically active men, SOD2 polymorphism has an influence on the resting level of oxidative stress marker in the blood without affecting both enzymatic and non-enzymatic antioxidant potential. In turn, both SOD1 and GPxl polymorphisms do not seem to affect oxidative-antioxidative status of the blood. However, the absence of mutant homozygotic genotypes (i.e. SOD1 CC and GPxl Leu/Leu) in the study group may indicate that these genotypes are disadvantageous, and thus underrepresented in young, healthy and physically fit men.

\section{References}

1. Ben-Zaken S., Eliakim A., Nemet D., Kassem E., Meckel Y. (2013). Increased prevalence of MnSOD genetic polymorphism in endurance and power athletes. Free Radical Research 47(12), 1002-1008. DOI:10.3109/10715762.2013.838627

2. Pani G., Colavitti R., Bedogni B., Anzevino R., Borrello S., Galeotti T. (2001). A redox signaling mechanism for density-dependent inhibition of cell growth. Journal of Biological Chemistry 275(49), 38891-9. DOI: 10.1074/jbc.M007319200

3. Radak Z., Chung H.Y., Goto S. (2008). Systemic adaptation to oxidative challenge induced by regular exercise. Free $R a-$ dical Biology \& Medicine 44(2), 153-159. DOI: 10.1016/j.freeradbiomed.2007.01.029

4. Montameni S., Taheri Chadorneshin H., Golestani A. (2020). Comparing the effects of resistance exercise type on serum levels of oxidative stress and muscle damage markers in resistance-trained women. Sport Sciences for Health 16, 443-450.
5. Zelko I., Mariani T., Folz R. (2002). Superoxide dismutase multigene family: a comparison of the CuZn-SOD (SOD1), Mn-SOD (SOD2), and EC-SOD (SOD3) gene structures, evolution, and expression. Free Radical Biology \& Medicine 33(3), 337-349. DOI: 10.1016/s0891-5849(02)00905-x

6. Powers S.K., Jackson M.J. (2008). Exercise-induced oxidative stress: Cellular mechanisms and impact on muscle force production. Physiological Reviews 88(4), 1243-1276. DOI: 10.1152/physrev.00031.2007

7. Akimoto A.K., Miranda-Vilela A.L., Alves P.C., Pereira L.C., Lordelo G.S., et al. (2010). Evaluation of gene polymorphism in exercise-induced oxidative stress and damage. Free Radical Research 44(3), 322-331. DOI: 10.3109/10715760903494176

8. Bolzan A.D., Bianchi M.S., Bianchi N.O. (1997). Superoxide dismutase, catalase and glutathione peroxidase activities in human blood: influence of sex, age and cigarette smoking. Clinical Biochemistry 30(6), 449-454. DOI: 10.1016/s00099120(97)00047-7

9. Nikolaidis M.G., Kyparos A., Hadziioannou M., Panou N., Samaras L., et al. (2007). Acute exercise markedly increases blood oxidative stress in boys and girls. Applied Physiology, Nutrition and Metabolism 32(2), 197-205. DOI: 10.1139/ h06-097

10. Tas A., Silig Y., Pinarbas H., Gürelik M. (2019). Role of SOD2 Alal6Val polymorphism in primary brain tumors. Biomedical Reports 10(3), 189-194. DOI: 10.3892/br.2019.1192

11. Ji L.L. (1998). Antioxidant enzyme response to exercise and training in the skeletal muscle. In: Reznick A.Z., Packer L., Sen C.K., Holloszy J.O., Jackson M.J. (eds), Oxidative stress in skeletal muscle (p. 103-125). Basel, Switzerland: Birkhäuser.

12. Bresciani G., Cruz I.B., de Paz J.A., Cuevas M.J., González-Gallego J. (2013). The MnSOD Alal6Val SNP: relevance to human diseases and interaction with environmental factors. Free Radical Research 47(10), 781-92. DOI: 10.3109/10715762.2013.836275

13. Yeh H.L., Kuo L.T., Sung F.C., Yeh C.C. (2018). Association between Polymorphisms of Antioxidant Gene (MnSOD, CAT, and GPxl) and Risk of Coronary Artery Disease. Biomed Research International 2018, 5086869. DOI: 10.1155/2018/5086869

14. Hiroi S., Harada H., Nishi H., Satoh M., Nagai R., Kimura A. (1999). Polymorphisms in the SOD2 and HLA-DRB1 Genes Are Associated with Nonfamilial Idiopathic Dilated Cardiomyopathy in Japanese. Biochemical and Biophysical Research Communications 261(2), 332-339. DOI: 10.1006/ bbrc.1999.1036

15. Jones D.A., Prior S.L., Tang T.S., Bain S.C., Hurel S.J., et al. (2010). Association between the rs4880 superoxide dismutase $2(\mathrm{C}>\mathrm{T})$ gene variant and coronary heart disease in diabetes mellitus. Diabetes Research and Clinical Practice 90(2), 196-201. DOI: 10.1016/j.diabres.2010.07.009

16. Bresciani G., González-Gallego J., da Cruz I.B., de Paz J.A., Cuevas M.J. (2013). The Alal6Val MnSOD gene polymorphism modulates oxidative response to exercise. Clinical Biochemistry 46(4-5), 335-40. DOI: 10.1016/j.clinbiochem.2012.11.020

17. Ahmetov I.I., Naumov V.A., Donnikov A.E., Maciejewska-Karłowska A., Kostryukova E.S., et al. (2014). SOD2 gene polymorphism and muscle damage markers in elite athletes. Free Radical Research 48(8), 948-55. DOI: 10.3109/10715762.2014.928410

18. Vecchio M., Currò M., Trimarchi F., Naccari S., Caccamo D., et al. (2017). The oxidative stress response in elite water polo 
players: Effects of genetic background. Biomed Research International 2017, 7019694. DOI: 10.1155/2017/7019694

19. Ravn-Haren G., Olsen A., Tjønneland A., Dragsted L.O., Nexø B.A., et al. (2006). Associations between GPXI Pro198Leu polymorphism, erythrocyte GPX activity, alcohol consumption and breast cancer risk in a prospective cohort study. Carcinogenesis 27(4), 820-825. DOI: 10.1093/carcin/ bgi267

20. Hu Y.J., Diamond A.M. (2003). Role of glutathione peroxidase 1 in breast cancer: loss of heterozygosity and allelic differences in the response to selenium. Cancer Research 63(12), 3347-3351.

21. Thu V.T., Kim H.K., Ha S.H., Yoo J.Y., Park W.S., et al. (2010). Glutathione peroxidase 1 protects mitochondria against hypoxia/reoxygenation damage in mouse hearts. Pflugers Archive - European Journal of Physiology 460(1), 55-68. DOI: 10.1007/s00424-010-0811-7

22. Ichimura Y., Habuchi T., Tschuiya N., Wang L., Oyama C., et al. (2004). Increased risk of bladder cancer associated with a glutathione peroxidase 1 codon 198 variant. The Journal of Urology 172, 728-732. DOI: 10.1097/01.ju $0000130942.40597 .9 \mathrm{~d}$

23. Ratnasinghe D., Tangrea J.A., Andersen M.R., Barrett M.J., Virtamo J., Taylor P.R. et al. (2000). Glutathione peroxidase codon 198 polymorphism variant increases lung cancer risk. Cancer Research 60(22), 6381-6383.

24. Forsberg L., de Faire U., Marklund S.L., Andersson P.M., Stegmayr B., Morgenstern R. (2000). Phenotype Determination of a Common Pro-Leu Polymorphism in Human Glutathione Peroxidase 1. Blood Cells, Molecules, and Diseases 26(5), 423-426. DOI: 10.1006/bcmd.2000.0325

25. Raaschou-Nielsen O., Sørensen M., Hansen R.D., Frederiksen K., Tjønneland A., et al. (2007). GPXl Prol98Leu polymorphism, interactions with smoking and alcohol consumption, and risk for lung cancer. Cancer Letters 247(2), 293-300. DOI: 10.1016/j.canlet.2006.05.006

26. Arsova-Sarafinovska Z., Matevska N., Eken A., Petrovski D., Banev S., et al. (2008). Glutathione peroxidase 1 (GPX1) genetic polymorphism, erythrocyte GPX activity, and prostate cancer risk. International Urology and Nephrology 41(1), 6370. DOI: $10.1007 /$ s11255-008-9407-y

27. Ghattas M.H., Abo-Elmatty D.N. (2012). Association of Polymorphic Markers of the Catalase and Superoxide Dismutase Genes with Type 2 Diabetes Mellitus. DNA and Cell Biology 31(11), 1598-1603. DOI: 10.1089/dna.2012.1739

28. Flekac M., Skrha J., Hilgertova J., Lacinova Z., Jarolimkova M. (2008). Gene polymorphisms of superoxide dismutases and catalase in diabetes mellitus. BMC Medical Genetics 9, 30. DOI: 10.1186/1471-2350-9-30

29. Panduru N.M., Cimponeriu D., Cruce M., Ion D.A., Moța E., et al. (2010). Association of $+35 \mathrm{~A} / \mathrm{C}$ (intron3/exon3) polymorphism in SODl-gene with diabetic nephropathy in type 1 diabetes. Romanian Journal of Morphology and Embryology 51(1), 37-41.

30. Akhy L.A., Deb P., Das M., Ali L., Faruque M.O., Hassan Z. (2014). Superoxide dismutase 1 gene $+35 \mathrm{~A}>\mathrm{C}$ (intron $3 /$ exon3) polymorphism in diabetic nephropathy patients among Bangladeshi population. Journal of Molecular Pathophysiology 3(4), 52-57.

31. Ukkola O., Erkkilä P.H., Savolainen M.J., Kesäniemi Y.A. (2001). Lack of association between polymorphisms of catalase, copper-zinc superoxide dismutase (SOD), extracellular SOD and endothelial nitric oxide synthase genes and macroangiopathy in patients with type 2 diabetes mellitus. Journal of Internal Medicine 249(5), 451-459. DOI: 10.1046/j.1365-2796.2001.00828.x

32. Nithya K., Angeline T., Isabel W., Asirvatham A.J. (2016). SODl Gene +35A/C (exon3/intron3) Polymorphism in Type 2 Diabetes Mellitus among South Indian Population. Genetics Research International 1, 1-5. DOI:10.1155/2016/3787268

33. Vats P., Sagar N., Singh T.P., Banerjee M. (2014). Association of Superoxide dismutases (SOD1 and SOD2) and Glutathione peroxidase $1(\mathrm{GPxl})$ gene polymorphisms with Type 2 diabetes mellitus. Free Radical Research 49(1), 17-24. DOI: 10.3109/10715762.2014.971782

34. Erdelmeier I., Gérard-Monnier D., Yadan J.C., Chaudière J. (1998). Reactions of N-methyl-2-phenylindole with malondialdehyde and 4-hydroxyalkenals. Mechanistic aspects of the colorimetric assay of lipid peroxidation. Chemical Research in Toxicology 11(10), 1176-1183. DOI: 10.1021/tx970180z

35. Graffelman J. (2015). Exploring Diallelic Genetic Markers: The Hardy Weinberg Package. Journal of Statistical Software 64(3), 1-23. DOI: 10.18637/jss.v064.i03

36. Bastaki M., Huen K., Manzanillo P., Chande N., Chen C., et al. (2006). Genotype-activity relationship for Mn-superoxide dismutase, glutathione peroxidase 1 and catalase in humans. Pharmacogenetics and Genomics 16(4), 279-86. DOI: 10.1097/01.fpc.0000199498.08725.9c

37. Fukai T., Ushio-Fukai M. (2011). Superoxide dismutases: role in redox signaling, vascular function, and diseases. Antioxidant E Redox Signaling 15(6), 1583-1606. DOI: 10.1089/ ars.2011.3999

38. Finaud J., Lac G., Filaire E. (2006). Oxidative stress: relationship with exercise and training. Sports Medicine 36(4), 327-358. DOI: 10.2165/00007256-200636040-00004

39. Azizbeigi K., Stannard S.R., Atashak S., Haghighi M.M. (2014). Antioxidant enzymes and oxidative stress adaptation to exercise training: comparison of endurance, resistance, and concurrent training in untrained males. Journal of Exercise Science \& Fitness 12, 1-6. DOI: 10.1016/j. jesf.2013.12.001

40. Jówko E., Gromisz W., Sadowski J., Cieśliński I., Kotowska J. (2017). SOD2 gene polymorphism may modulate biochemical responses to a 12-week swimming training. Free Radical Biology and Medicine 13, 571-579. DOI: 10.1016/j.freeradbiomed.2017.11.002

41. Jówko E., Gierczuk D., Cieśliński I., Kotowska J. (2017). SOD2 gene polymorphism and response of oxidative stress parameters in young wrestlers to a three-month training. Free Radical Research 51(5), 506-516. DOI: 10.1080/10715762.2017.1327716

42. Duarte M.M., Moresco R.N., Duarte T., Santi A., Bagatini M.D., et al. (2010). Oxidative stress in hypercholesterolemia and its association with Alal6Val superoxide dismutase gene polymorphism. Clinical Biochemistry 43(13-14), 111823. DOI: 10.1016/j.clinbiochem.2010.07.002

43. Chen H., Yu M., Li M., Zhao R., Zhu Q., et al. (2012). Polymorphic variations in manganese superoxide dismutase (MnSOD), glutathione peroxidase-1 (GPXI), and catalase (CAT) contribute to elevated plasma triglyceride levels in Chinese patients with type 2 diabetes or diabetic cardiovascular disease. Molecular and Cellular Biochemistry 363(12), 85-91. DOI: 10.1007/s11010-011-1160-3

44. Montano M.A., Barrio Lera J.P., Gottlieb M.G., Schwanke C.H., da Rocha M.I., et al. (2009). Association between manganese superoxide dismutase (MnSOD) gene polymor- 
phism and elderly obesity. Molecular and Cellular Biochemistry 328(1-2), 33-40. DOI: 10.1007/s11010-009-0071-z

45. Tang N.P., Wang L.S., Yang L., Gu H.J., Sun Q.M., et al. (2008). Genetic variant in glutathione peroxidase 1 gene is associated with an increased risk of coronary artery disease in a Chinese population. Clinica Chimica Acta 395(1-2), 8993. DOI: 10.1016/j.cca.2008.05.013

46. Buraczyńska M., Buraczyńska K., Dragan M., Książek A. (2017). Pro198Leu Polymorphism in the Glutathione Peroxidase 1 Gene Contributes to Diabetic Peripheral Neuropathy in Type 2 Diabetes Patients. Neuromolecular Medicine 19, 147-153. DOI: 10.1007/s12017-016-8438-2

Submitted: November 3, 2020

Accepted: December 13, 2020 